\section{ABCS}

How to cite this article: Muradas et al. Determining factors in the development of coronary plates and obstructions. ABCS Health Sci. 2020;45:e020015. https://doi. org/10.7322/abcshs.45.2020.1340

Received: Oct 04, 2019

Revised: Feb 10, 2020

Approved: Mar 03, 2020

Corresponding author: Daniel Vicentini de Oliveira - Universidade Cesumar Departamento de pós-graduação Stricto Sensu em Promoção da Saúde - Avenida Guedner, 1610 - CEP: 87050-900 - Maringá (PR), Brazil - Email: d.vicentini@ hotmail.com

Declaration of interests: nothing to declare

This is an open access article distributed under the terms of the Creative Commons Attribution License

(C) 2020 Muradas et al.

\title{
Determining factors in the development of coronary plates and obstructions
}

\author{
Soraya Andrea Delefrate Muradas ${ }^{1}$, Amanda Sayuri Nakamura², Jader Dornelas Neto², \\ Taisa Valques Lorecente ${ }^{3}$, Daniel Vicentini de Oliveira ${ }^{1}$, Mirian Ueda Yamaguchi ${ }^{1}$ \\ ${ }^{1}$ Departamento de Pós-Graduação Stricto Sensu em Promoção da Saúde, Universidade Cesumar \\ (UNICESUMAR) - Maringá (PR), Brazil. \\ ${ }^{2}$ Departamento de Graduação em Medicina (UNICESUMAR) - Maringá (PR), Brazil. \\ 3Departamento de Graduação em Biomedicina (UNICESUMAR) - Maringá (PR), Brazil.
}

\begin{abstract}
Introduction: Coronary artery disease is the largest cause of mortality in the world. The main risk factors for its development include systemic arterial hypertension and type 2 diabetes mellitus. Objective: To search for predictors of the development of plaques and obstructions in coronary arteries and to determine whether the exercise test is a reliable pretest for coronary angiotomography. Methods: 883 computed tomography reports of coronaries were analyzed. Sociodemographic information, health conditions and results of the exercise test from patients were collected, along with calcium score, percentile and number of arterial segments with significant obstruction. The data were analyzed using descriptive and inferential statistics. Significance was considered for $\mathrm{p}<0.05$. Results: It observed that the statistically significant predictors to the calcium score were male, being over 60 years old, having type 2 diabetes mellitus and systemic arterial hypertension. There was no relationship with high BMI and coronary obstruction. Regarding the exercise test, it was possible to observe that the majority of individuals who were positive in the exercise test, did not have a positive calcium score or significant coronary obstructions. Conclusion: The predictors for the development of coronary plaques and obstructions were male, aged $\geq 60$ years, having type 2 diabetes mellitus and systemic arterial hypertension.
\end{abstract}

Keywords: cardiovascular diseases; coronary disease; angiography; atherosclerosis; life style.

\section{INTRODUCTION}

Coronary artery disease (CAD) is the main cause of mortality in the world, responsible for 7.25 million deaths, which corresponds to $12.8 \%$ of the total deaths per year ${ }^{1}$. Knowing that in at least half of people with CAD, acute myocardial infarction is the first manifestation, the identification of asymptomatic individuals is crucial for effective prevention and the correct development of therapeutic goals ${ }^{2}$.

The main risk factors for the development of coronary heart disease include age, sex, family history, systemic arterial hypertension (SAH), smoking, dyslipidemia, overweight and type 2 diabetes mellitus (DM2) ${ }^{3}$. The leading cause of death in individuals with diabetes is cardiovascular disease, accounting for half of deaths from diabetes in most countries ${ }^{4}$. 
Knowing the high incidence of CAD, it is important to identify the determinants related to the disease and its correct diagnosis, so that prevention and consequent implementation of actions to reduce the indexes found are elaborated.

Thus, this study aimed to detect the predictors for the development of coronary plaques and obstructions detected by computed tomography of coronary arteries, a gold standard exam in the area, in addition to determining if the stress test is a reliable pretest for coronary angiotomography.

\section{METHODS}

This study was approved by the Ethics and Research Committee of the Centro Universitário de Maringá (Process No. 1,359,730).

\section{Sample}

Quantitative, observational and retrospective study, carried out by analyzing 1048 reports of computed tomography (TCcor) exams composed of coronary angiography (CA) and calcium score (CS) of patients referred for CAD investigation in January 2012 to December 2014 at a reference imaging clinic, located in the city of Maringá - Paraná, this sample being the total number of tests performed in this period. Due to the retrospective characteristic of the collected data, there was no need to collect signatures for the informed consent form.

Of the 1,048 reports of TCcor exams, 883 were selected for analysis, since the others were excluded because they fit the exclusion criteria. Examinations with unavailability of data were excluded from the study, in addition to those that contained as an indication for carrying out: assessment of cardiac masses; congenital heart disease; valve disease, post stent placement, post cardiac transplant and post coronary revascularization. The selected reports were those that indicated risk stratification for coronary heart disease.

\section{Assessed variables}

The data collection of the reports was based on the identification and capture of four pieces of information: result of CS, CA, description of predictive factors and result of exercise stress test (ST).

The CS, measured in a Hounsfield unit (HU), was classified as negative if $=0$, and positive $>0$. The CA assessed the percentage of obstruction in 56 coronary segments (14 coronary arteries divided into four segments each, with the artery ostium, proximal, middle and distal branch), was classified according to the number of segments with significant luminal obstruction: none obstructed segment; one to three segments; four or more segments, being considered "without significant luminal reduction" when the obstruction was below $50 \%$, and "with significant luminal reduction", obstruction of $50 \%$ or more of the coronary artery ${ }^{5}$.

The Hounsfield scale used in the examination is a quantitative scale that describes radiodensity. The radiodensity of distilled water and air under standard conditions of temperature and pressure corresponds respectively to 0 and $-1000 \mathrm{HU}$.

Among the factors intrinsic to the patient, the following information was collected from the reports: age, sex, body mass index (BMI) $\left(\mathrm{Kg} / \mathrm{m}^{2}\right)$, smoking, family history and presence of associated chronic diseases (DM2, dyslipidemia and SAH).

The result of the exercise stress test was included in the TCcor report for patients who had previously undergone ST before TCcor. The result of the stress test can be positive, inconclusive or negative for myocardial ischemia.

\section{Statistical Analysis}

The data were tabulated in a Microsoft Office Excel spreadsheet and in order to investigate the associations between the CS result and the number of segments with significant luminal reduction, with the possible predictive factors, the odds ratios were calculated. Subsequently, using the methodology proposed by Hosmer and Lemeshow ${ }^{6}$, the factors that showed at least a moderate association ( $\mathrm{p}>0.25)$ with the TCcor result were selected using the chi-square test. Such factors were included in the multivariate model, which estimates the odds ratio considering the possible interactions between the variables.

The $\chi^{2}$ score test was applied to verify the assumption of proportional odds. Both for univariate analyzes and for the adjusted multivariate model, there was sample evidence that the proportional odds model was adequate to adjust the data, considering a $5 \%$ level of significance. Statistical analyzes were performed using the SAS (Statistical Analysis System) software, version 9.3.

Aiming to evaluate the possible association between the result of st with the number of obstructions in the arteries, as well as the CS, the chi-square test $\left(\chi^{2}\right)$ was applied in both situations, setting the level of $5 \%$ of significance, with the aid of the $R$ (R Development Core Team) statistical environment.

\section{RESULTS}

The results presented in Table 1 show that $48.92 \%$ of the evaluated exams presented a negative result for CS. It is noted that male patients have almost twice the chances of obtaining a positive CS result compared to women with (odds ratio $\mathrm{OR}=1.98$ ). It was also found that the chances of individuals who are 60 years old or older to have positive CS represent five times more chances compared to those between 40 and 60 years old $(\mathrm{OR}=5.03)$, while individuals younger than 40 years old had chances significantly smaller.

It is estimated that patients with SAH are twice as likely to obtain a positive calcium score as compared to non-hypertensive patients $(\mathrm{OR}=2.01)$. Those with DM2 are $153 \%$ more likely to have a positive outcome compared to their peers. The presence of dyslipidemia is also a factor that significantly increases the patient's 
chances of having a positive $\mathrm{CS}(\mathrm{OR}=1.56)$. It was found that patients who declared to be ex-smokers are almost twice as likely $(\mathrm{OR}=1.91)$ to obtain a positive calcium score.

It is also possible to notice that the factors sex, age, SAH, DM2, dyslipidemia and ex-smoking, have a significant association with the result of CS, considering a level of 5\%. In addition to these variables, BMI was also included in the multivariate logistic regression model, as it presented at least a moderate association, with a p-value of 0.09 , less than 0.25 .

It can be seen in Table 2, the male gender, the age above 60 years and the presence of chronic diseases SAH and DM2 remained as determining factors, considering the significant increase in the chances of obtaining a positive result for CS, when analyzed together, while the age of less than 40 years remained a determining factor of protection. It is noteworthy that the estimated odds ratios for male individuals were much higher in the joint analysis, with men being about four times more likely to have a positive CS when compared to women $(\mathrm{OR}=4.15)$.

Just as the univariate and multivariate analysis of factors related to CS was performed, the same method was used to analyze the percentage of coronary obstruction.
Table 2: Multivariate analysis of the calcium score (CS).

\begin{tabular}{|c|c|c|c|}
\hline Factors & $\begin{array}{l}\text { Adjusted } \\
\text { OR }\end{array}$ & CI 95\% & P value \\
\hline \multicolumn{4}{|l|}{ Sex } \\
\hline Female & 1.00 & - & - \\
\hline Male & 4.15 & $2.86-6.03$ & $<0.01^{*}$ \\
\hline \multicolumn{4}{|l|}{ Age } \\
\hline$<40$ years & 0.06 & $0.01-0.25$ & $<0.01^{*}$ \\
\hline $40 \mathrm{l}-60$ years & 1.00 & - & - \\
\hline$\geq 60$ years & 6.98 & $4.85-10.06$ & $<0.01^{*}$ \\
\hline \multicolumn{4}{|l|}{ BMI } \\
\hline Underweight & - & - & - \\
\hline Normal & 1.00 & - & - \\
\hline Overweight & 1.42 & $0.96-2.09$ & 0.08 \\
\hline Obesity & 1.32 & $0.86-2.04$ & 0.21 \\
\hline \multicolumn{4}{|c|}{ Systemic Arterial Hypertension } \\
\hline No & 1.00 & - & - \\
\hline Yes & 1.38 & $0.99-1.91$ & $0.05^{\star}$ \\
\hline \multicolumn{4}{|c|}{ Type 2 Diabetes Mellitus } \\
\hline No & 1.00 & - & - \\
\hline Yes & 1.74 & $1.14-2.67$ & $0.01^{*}$ \\
\hline \multicolumn{4}{|l|}{ Dyslipidemia } \\
\hline No & 1.00 & - & - \\
\hline Yes & 1.24 & $0.90-1.71$ & 0.19 \\
\hline \multicolumn{4}{|l|}{ Ex-smoker } \\
\hline No & 1.00 & - & - \\
\hline Yes & 1.34 & $0.87-2.06$ & 0.18 \\
\hline
\end{tabular}

BMI: body mass index; $\mathrm{Cl}$ : confidence interval; OR: odds ratio.

Table 1: Univariate analysis of the result of the calcium score (CS).

\begin{tabular}{|c|c|c|c|c|c|c|}
\hline \multirow{2}{*}{ Factors } & \multicolumn{2}{|c|}{ CS } & \multirow{2}{*}{$\begin{array}{c}\text { Gross } \\
\text { OR }\end{array}$} & \multirow{2}{*}{ Cl $95 \%$} & \multirow{2}{*}{ P value } & \multirow{2}{*}{$\begin{array}{l}\text { P value } \\
\chi^{2} \text { test }\end{array}$} \\
\hline & Negative & Positive & & & & \\
\hline \multicolumn{7}{|l|}{ Sex } \\
\hline Female & 173 & 114 & 1.00 & - & - & \multirow{2}{*}{$<0.01^{*}$} \\
\hline Male & 259 & 337 & 1.98 & $1.48-2.63$ & $<0.01$ & \\
\hline \multicolumn{7}{|l|}{ Age } \\
\hline$<40$ years & 52 & 2 & 0.06 & $0.02-0.26$ & $<0.01$ & \multirow{3}{*}{$<0.01^{*}$} \\
\hline $401-60$ years & 296 & 185 & 1.00 & - & - & \\
\hline$\geq 60$ years & 84 & 264 & 5.03 & $3.70-6.83$ & $<0.01$ & \\
\hline \multicolumn{7}{|l|}{ BMI } \\
\hline Underweight * & 0 & 3 & & & & \multirow{4}{*}{0.09} \\
\hline Normal & 125 & 105 & 1.00 & - & - & \\
\hline Overweight & 186 & 204 & 1.31 & $0.94-1.81$ & 0.96 & \\
\hline Obesity & 121 & 139 & 1.37 & 0.96-1.95 & 0.96 & \\
\hline \multicolumn{7}{|c|}{ Systemic Arterial Hipertension } \\
\hline No & 251 & 184 & 1.00 & - & - & \multirow{2}{*}{$<0.01^{*}$} \\
\hline Yes & 181 & 267 & 2.01 & $1.54-2.63$ & $<0.01$ & \\
\hline \multicolumn{7}{|c|}{ Type 2 diabetes mellitus } \\
\hline No & 379 & 333 & 1.00 & - & - & \multirow{2}{*}{$<0.01^{*}$} \\
\hline Yes & 53 & 118 & 2.53 & $1.78-3.62$ & $<0.01$ & \\
\hline \multicolumn{7}{|l|}{ Dyslipidemia } \\
\hline No & 251 & 212 & 1.00 & - & - & \multirow{2}{*}{$<0.01^{*}$} \\
\hline Yes & 181 & 239 & 1.56 & $1.20-2.04$ & $<0.01$ & \\
\hline \multicolumn{7}{|l|}{ Smoker } \\
\hline No & 389 & 403 & 1.00 & - & - & \multirow{2}{*}{0.74} \\
\hline Yes & 43 & 48 & 1.08 & $0.70-1.66$ & 0.74 & \\
\hline \multicolumn{7}{|l|}{ Ex-smoker } \\
\hline No & 379 & 356 & 1.00 & - & - & \multirow{2}{*}{$<0.01^{*}$} \\
\hline Yes & 53 & 95 & 1.91 & $1.32-2.75$ & $<0.01$ & \\
\hline \multicolumn{7}{|l|}{ Family history } \\
\hline No & 315 & 333 & 1.00 & - & - & \multirow{2}{*}{0.76} \\
\hline Yes & 117 & 118 & 0.95 & $0.71-1.29$ & 0.76 & \\
\hline
\end{tabular}

*Statistically significant values for $p \leq 0.05$.

BMI: body mass index; $\mathrm{Cl}$ : confidence interval; OR: odds ratio. 
Table 3 shows the univariate analysis and Table 4 the multivariate analysis, related to the degree and number of segments with significant luminal reduction.

Regarding the number of blocked artery segments, $77.91 \%$ of the exams evaluated did not present any obstruction, $18.57 \%$ had 1 to 3 obstructed segments and only $3.52 \%$ had 4 or more. It is estimated that the chances of a male patient having a higher number of obstructions are $70 \%$ greater than the chances of women. As for age, it is observed that the chances of having more obstructed segments significantly increase for patients over 60 years of age compared to those who are in the 40 to 60 age group, and even for individuals under 40 years of age, the chances are one third in relation to the aforementioned range. It is also possible to note that patients who have SAH, DM2 and dyslipidemia have significantly greater chances that the number of obstructions is greater, when compared to those who do not have these diseases. Still, it is estimated that ex-smokers have a $50 \%$ greater chance of presenting a greater number of obstructions than those who have not smoked in the past. No other characteristic provided significant differences in the ratio of chances of presenting a greater number of obstructions.
All the factors mentioned above, sex, age, SAH, DM2, dyslipidemia and ex-smoker, are significantly associated with the number of obstructions at the $5 \%$ level of significance, according to the chi-square test. The other factors that presented $p$ value $>0.25$, were not included in the multivariate ordinal logistic model, the results of which are shown in Table 4.

Only the variables male gender, age over 60 years and the presence of DM2, remained as predictive factors for presenting a greater number of obstructed artery segments, with the significance level set at 5\%, indicated in Table 4 . The difference in odds ratio of the other characteristics were not significant.

Among the patients who presented negative results for the calcium score, (97.22\%) did not present any segment of artery with obstruction, while for those who obtained positive CS, a total of $40.57 \%$ had 1 or more segments of arteries with degree of obstruction greater than $50 \%$.

It was found that, at $5 \%$ level of significance, there is sample evidence that confirms the significant association between the result of the calcium score and the number of blocked artery segments.

Table 3: Univariate analysis of the number of coronary obstructions.

\begin{tabular}{|c|c|c|c|c|c|c|c|}
\hline \multirow{2}{*}{ Factors } & \multicolumn{3}{|c|}{ Number of coronary obstructions } & \multirow{2}{*}{$\begin{array}{c}\text { Gross } \\
\text { OR }\end{array}$} & \multirow{2}{*}{$\mathrm{Cl} 95 \%$} & \multirow{2}{*}{ P value } & \multirow{2}{*}{$\frac{\chi^{2} \text { test }}{\text { P Value }}$} \\
\hline & 0 & 1 to 3 & 4 or more & & & & \\
\hline \multicolumn{8}{|l|}{ Sex } \\
\hline Female & 240 & 41 & 6 & 1.00 & - & - & \multirow{2}{*}{$0.01^{*}$} \\
\hline Male & 448 & 123 & 25 & 1.70 & $1.18-2.44$ & $<0.01$ & \\
\hline \multicolumn{8}{|l|}{ Age } \\
\hline$<40$ years & 51 & 3 & 0 & 0.33 & $0.10-1.08$ & $<0.01$ & \multirow{3}{*}{$<0.01^{*}$} \\
\hline $401-60$ years & 408 & 63 & 10 & 1.00 & - & - & \\
\hline$\geq 60$ years & 229 & 98 & 21 & 2.91 & $2.09-4.06$ & $<0.01$ & \\
\hline \multicolumn{8}{|l|}{$\mathrm{BMI}$} \\
\hline Underweight ${ }^{*}$ & 3 & 0 & 0 & & & & \multirow{4}{*}{0.46} \\
\hline Normal & 179 & 41 & 10 & 1.00 & - & - & \\
\hline Overweight & 309 & 73 & 8 & 0.90 & $0.61-1.33$ & 0.97 & \\
\hline Obesity & 197 & 50 & 13 & 1.13 & $0.74-1.71$ & 0.97 & \\
\hline \multicolumn{8}{|c|}{ Systemic Arterial Hypertension } \\
\hline No & 361 & 66 & 8 & 1.00 & - & - & \multirow{2}{*}{$<0.01^{*}$} \\
\hline Yes & 327 & 98 & 23 & 1.84 & $1.33-2.54$ & $<0.01$ & \\
\hline \multicolumn{8}{|c|}{ Type 2 Diabetes Mellitus } \\
\hline No & 585 & 113 & 14 & 1.00 & - & - & \multirow{2}{*}{$<0.01^{*}$} \\
\hline Yes & 103 & 51 & 17 & 3.19 & $2.24-4.56$ & $<0.01$ & \\
\hline \multicolumn{8}{|l|}{ Dyslipidemia } \\
\hline No & 380 & 74 & 9 & 1.00 & - & - & \multirow{2}{*}{$<0.01^{*}$} \\
\hline Yes & 308 & 90 & 22 & 1.70 & $1.23-2.34$ & $<0.01$ & \\
\hline \multicolumn{8}{|l|}{ Smoker } \\
\hline No & 621 & 143 & 28 & 1.00 & - & - & \multirow{2}{*}{0.51} \\
\hline Yes & 67 & 21 & 3 & 1.28 & $0.78-2.10$ & 0.33 & \\
\hline \multicolumn{8}{|l|}{ Ex-smoker } \\
\hline No & 581 & 133 & 21 & 1.00 & - & - & \multirow{2}{*}{$0.04^{*}$} \\
\hline Yes & 107 & 31 & 10 & 1.50 & $1.01-2.22$ & 0.05 & \\
\hline \multicolumn{8}{|l|}{ Family history } \\
\hline No & 502 & 122 & 24 & 1.00 & - & - & \multirow{2}{*}{0.82} \\
\hline Yes & 186 & 42 & 7 & 0.90 & $0.63-1.30$ & 0.58 & \\
\hline
\end{tabular}

*Statistically significant values for $p \leq 0.05$.

BMI: body mass index; $\mathrm{Cl}$ : confidence interval; OR: odds ratio. 
In the analysis between the relationship between exercise testing and the result of TCcor, 241 exams were included, since of the 883 complete exams, 241 had performed the ST prior to the coronary angiotomography exam.

In general, most patients who underwent ST had a positive result (69.29\%), 20.74\% had an indefinite result and the smallest part (9.95\%), a negative result for myocardial ischemia.

As for the number of obstructions, it is observed that most had no obstruction with a degree greater than $50 \%, 14.93 \%$ had significant obstruction in 1 to 3 coronary segments, and $3.73 \%$ had more than 4 segments with obstruction. As for the calcium score, $52.28 \%$ of the individuals had a negative result and $47.71 \%$ positive.

When stress testing is related to TCcor, most patients presented positive ST for myocardial ischemia and did not present any obstruction. Only $13.68 \%$ of the individuals confirmed the test was positive and had coronary obstructions $(3.31 \%$ with 4 or more obstructions and $10.37 \%$ with 1 to 3 obstructions).

If we observe the relationship between ST and calcium score, the discrepancy was smaller, since $35.68 \%$ had positive ST and negative CS, whereas $33.60 \%$ had positivity in the 2 tests.

No statistically significant difference was found in the relationship between CTcor and CS with ST.

\section{DISCUSSION}

Among the main findings of this study, the relationship of risk for the development of coronary obstructions in elderly male individuals with type 2 diabetes mellitus stands out, as well as the low relationship between the presence of coronary obstruction and positivity in the effort.

Table 4: Multivariate analysis of the number of obstructions.

\begin{tabular}{|c|c|c|c|}
\hline Factors & $\begin{array}{c}\text { Adjusted } \\
\text { OR }\end{array}$ & Cl 95\% & $P$ value \\
\hline \multicolumn{4}{|l|}{ Sex } \\
\hline Female & 1.00 & - & - \\
\hline Male & 2.47 & $1.66-3.67$ & $<0.01^{*}$ \\
\hline \multicolumn{4}{|l|}{ Age } \\
\hline$<40$ years & 0.37 & $0.11-1.24$ & 0.11 \\
\hline $401-60$ years & 1.00 & - & - \\
\hline$\geq 60$ years & 2.91 & $2.04-4.14$ & $<0.01^{*}$ \\
\hline \multicolumn{4}{|c|}{ Systemic Arterial Hypertension } \\
\hline No & 1.00 & - & - \\
\hline Yes & 1.25 & $0.87-1.79$ & 0.22 \\
\hline \multicolumn{4}{|c|}{ Type 2 Diabetes Mellitus } \\
\hline No & 1.00 & - & - \\
\hline Yes & 2.36 & $1.60-3.49$ & $<0.01^{*}$ \\
\hline \multicolumn{4}{|l|}{ Dyslipidemia } \\
\hline No & 1.00 & - & - \\
\hline Yes & 1.37 & $0.97-1.94$ & 0.08 \\
\hline \multicolumn{4}{|l|}{ Ex-smoker } \\
\hline No & 1.00 & - & - \\
\hline Yes & 1.09 & $0.71-1.67$ & 0.70 \\
\hline
\end{tabular}

*Statistically significant values for $\mathrm{p} \leq 0.05$

BMI: body mass index; $\mathrm{Cl}$ : confidence interval; OR: odds ratio.
Cardiovascular diseases continue to be the main cause of mortality and morbidity worldwide and the detection of their predictive factors, in particular for $\mathrm{CAD}$, has been of great importance for the development of primary prevention strategies ${ }^{7}$. The calcium score and coronary angiography, which make up the TCcor, have been shown to be an ally in the diagnosis and investigation of coronary atherosclerotic diseases, since they are more accurate than other diagnostic methods ${ }^{8}$.

The result of this research indicates that there is a significant association for calcium score and coronary obstructions, since coronary artery calcification (CAC) is most often related to a greater degree of stenosis and number of obstructed segments. The CS examination can contribute to the diagnosis of $\mathrm{CAD}$, since the cost of the CS examination performed in isolation is lower, making it more accessible to the population. This indication corroborates the study carried out by Ferreira et al. ${ }^{9}$ who, when analyzing the cost-effectiveness of diagnostic methods such as stress testing, myocardial scintigraphy, echocardiography, TCcor, CS and catheterization, concluded that angiotomography can be reserved for individuals with calcium score $>0$, and TCcor was considered the most cost-effective method among the analyzed tests, and can be used as a first-line test.

In contrast, work carried out with 291 patients undergoing coronary angiotomography, determined that an $\mathrm{CS}=0$ does not rule out the occurrence of significant stenosis, however this result was restricted to individuals with acute coronary syndrome ${ }^{10}$.

The minority of individuals had CS equal to 0 and with 1 to 3 coronary obstructions, in contrast, no report had a total absence of CAC associated with 4 or more affected segments. Coronary CS provides important prognostic information that is essential to alter clinical management, therefore, performing CS alone is more indicated when the objective is to stratify cardiovascular risk in asymptomatic patients, while CA provides a detailed assessment of the anatomy of coronary arteries with excellent accuracy. The results obtained from the CA are incremental when compared to the CS, so currently coronary angiotomography is not indicated when the goal is only stratification of global cardiovascular risk in asymptomatic patients ${ }^{11}$.

Regarding the degree of coronary obstruction, in this study it was possible to observe that more than half of the individuals submitted to the exam did not present any obstructed artery among the 56 analyzed segments, although this research did not calculate the predictive values, this finding is similar to the study Accuracy ${ }^{12}$, where it was concluded that the negative predictive value of TCcor (99\%) was greater than the positive predictive value, situated between $48 \%$ and $64 \%$.

In this research it was possible to observe that both in the association of CS and in coronary stenosis, the individual belonging to the male sex is a strong determinant for a higher risk of CAD, in contrast, a study similar to this one did not find any relationship between the 
male sex and the presence of coronary obstructions after analysis of 355 TCcor reports. The same occurred in the variables smoking and hypertension, which in the study cited found a significant relationship between these factors and obstruction of coronary artery light. The only predictive factor that resembled this research was the association of DM2 with the positive result for coronary stenosis ${ }^{13}$.

On the other hand, Won et al. ${ }^{14}$ confirmed the relationship between males and the risk of CAD. After evaluating 1690 patients with coronary artery occlusions, the researchers concluded that although women were significantly older and hypertensive than men, male subjects had a higher prevalence of coronary obstructions, a statistically significant result when compared to females.

The same hypothesis was confirmed when compared to a crosssectional and prospective study, which used TCcor reports from 509 patients and analyzed the predictive factor for coronary heart disease risk. Oliveira et al. ${ }^{15}$ concluded that belonging to the male gender is a determining factor for significant obstructions and $\mathrm{CS} \geq 100$. While $\mathrm{SAH}$ was a factor related to partially calcified plaques. In the same study, they identified that among the main determining factors for the development of CAD was dyslipidemia, although in the present study we did not find a significant relationship between dyslipidemia and the presence of calcification and coronary stenosis. When associated with the other predictive factor, this variable, analyzed individually, presented significance for both the development of CAC and for coronary obstructions.

Changes in blood cholesterol levels have a strong relationship with the development of coronary diseases, mainly in the formation of atherosclerotic plaques, and HDL (high density lipoprotein) works as a protector for the evolution of $\mathrm{CAD}^{16-21}$. This fact partially corroborates with the present research, since dyslipidemia was correlated with both the presence of calcification and coronary obstruction when analyzed in isolation, however, when related to the other predictive factors, this was not significant.

It was possible to observe that both in the relationship between CS and CA, DM2 was statistically significant as a high potential determinant for the development of CAD. A study carried out with 90 diabetic individuals between 40 and 65 years of age, using TCcor as an evaluation, demonstrated that asymptomatic diabetic patients had a high prevalence of coronary obstructions, affecting two or more coronary segments ${ }^{22}$. So also in a study carried out with 3,544 individuals that associated DM2 and precordial pain indicative of myocardial ischemia, found a relationship between hyperglycemia and pain suggestive of $\mathrm{CAD}^{23}$.

The finding that there is a higher mortality due to cardiovascular factors in the diabetic population, and that those using insulin have a higher risk of events has already been described ${ }^{24}$. The predisposition of diabetics for CAD is not yet clear, since some researchers suggest the potential direct effect of endothelial dysfunction to insulin ${ }^{25}$, and others show that the use of insulin is a marker of severity and duration of DM2. With greater severity, these individuals are likely to have more hyperglycemic crises that generate a consequent increase in oxidative stress and the presence of atherogenic particles in the vascular endothelium ${ }^{26}$.

Although none of the analyzes in the present study showed a significant relationship between BMI and risk for coronary atherosclerotic diseases, a prospective study conducted with 3275 adults between 18 and 30 years old, confirmed through TCcor that the presence of obesity and also fat abdominal pain for a long time is associated with coronary heart disease, and preventing or delaying the onset of obesity in young adults can decrease the risk of developing atherosclerosis ${ }^{27}$. In order to prevent the individual from being overweight and consequently preventing the risk for the development of CAD, it is important to practice physical exercises, since another study carried out with 4872 individuals demonstrated that the improvement of physical fitness is favorable for the prevention of cardiovascular disease risks. however, this improvement caused by exercise was observed through the relationship with myocardial hypertrophy, but there was no significant association when associated with the calcium score ${ }^{28}$.

However, it is noteworthy that in this study, despite the BMI having no significance for the development of CAC and coronary obstructions, individuals with overweight and obesity were more likely to have CAD risks through the analysis of odds ratios.

For the age factor, in this research the relationship with CS and CA was statistically significant for individuals aged 60 years or older to develop an accumulation of calcified plaques and consequent coronary obstructions. In a survey carried out through the analysis of 1,850 participants that aimed to determine the predictors for arterial aging, they did not find a relationship between the factors age, sex and ethnicity with the calcium score when analyzed in isolation, however, it was possible to conclude that healthy arterial aging is influenced by the long-term maintenance of modifiable risk factors ${ }^{29}$.

Many recent studies show the genetic relationship as a predictor for coronary artery disease $\mathrm{s}^{1430-32}$, a factor that despite being widely cited in the literature, has not been explored in this study, so this predictive factor is not yet well understood, it was noted that other studies published did not find this association ${ }^{33,34}$.

Even if an individual has no predictive factor, research shows that a 50 -year-old with no exposure to risk factors has a $6 \%$ chance of developing CAD in 10 years. The knowledge of the modifiable determinants allows the creation of efficient preventive strategies for the development of health actions, aimed at promoting the quality of life in the population ${ }^{33,35}$.

Regarding the ST, despite being an accepted test for the diagnosis of cardiovascular diseases, it is also used in the prognostic determination in the medical field for the detection of myocardial ischemia, in this study this fact was not confirmed, since the majority of patients with positive results in ST they did not present coronary artery obstructions. This finding is similar to the research carried out by Oliveira ${ }^{36}$, where the specificity of the stress test was high (93\%), 
however, the sensitivity was low in asymptomatic patients, concluding then a low accuracy of the test to detect myocardial ischemia.

It is noteworthy that of the small part of the individuals in this study who presented negative ST, most did not have any coronary obstruction, however a small percentage of these individuals, even with the negativity in the exercise test, presented from 1 to 3 coronary obstructions. None of these with negative ST had 4 or more obstructions, thus proving the specificity of the exercise test.

Fornitano and Godoy ${ }^{37}$ proved after the evaluation of 165 patients, that when an individual presents a double product (resulting from the multiplication of systolic blood pressure by the heart rate, which evaluates ventricular function), this data can be considered an important variable to predict the absence significant obstructive coronary disease, even when the exercise test is positive for myocardial ischemia. This information can be useful in complementing the ST even when positive, so that the individual can be referred to a higher cost exam, such as TCcor.

Despite the results, this study has some limitations that deserve to be highlighted. The design is transversal, which prevents inferring causality; these are the results of a single population group, preventing their generalization. Therefore, it is suggested that studies with larger samples and in different regions be performed, so that it can be proved that DM2 is a more significant predictor than other factors, such as hypercholesterolemia, overweight and SAH, and that ST is not a reliable pre-test for referral to perform TCcor.

The investigation of the data allowed us to conclude that the main predictive factors associated with the development of arterial calcification and obstruction of the coronary arteries were age $\geq 60$ years, belonging to the male gender and presenting DM2. Regarding CS, the main predictive factors were the same, with the inclusion of the predictive factor SAH. It was also possible to conclude that the CS and the CA present a statistically significant association.

Regarding the ST, there is no evidence to state that both the number of obstructions and the result of the calcium score are significantly associated with the result of the exercise test, for the patients who performed it. Therefore, it is suggested to readjust the objective of requesting the exercise test examination, since there is no relationship with coronary obstruction or altered calcium score.

\section{REFERENCES}

1. World Health Organization (WHO). Global status report on noncommunicable diseases 2010. Geneva: World Health Organization, 2010.

2. Arif S, Bartuś S, Dziewierz A, Chyrchel M, Brzeziński M, Rakowski T, et al. Impact of coronary artery disease presence on the long-term follow-up of carotid artery stenting. Kardiol Pol. 2015;73(4):274-9. http://doi.org/10.5603/KP.a2014.0217

3. Van Kempen BJ, Ferket BS, Hofman A, Steyerberg EW, Colkesen EB, Boekholdt SM, et al. Validation of a model to investigate the effects of modifying cardiovascular disease (CVD) risk factors on the burden of CVD: the rotterdam ischemic heart disease and stroke computer simulation (RISC) model. BMC Med. 2012;10(1):158. http://doi.org/10.1186/1741-7015-10-158

4. Sociedade Brasileira de Diabetes (SBD). Diretrizes da Sociedade Brasileira de Diabetes: 2017-2018. São Paulo: Clannad, 2017.

5. Bittencourt MS, Gowdak LHW. Uso da angiografia coronária por tomografia computadorizada na avaliação prognóstica de pacientes com suspeita de doença arterial coronária. Tese (Doutorado) - Universidade de São Paulo. São Paulo: 2014.

6. Hosmer Jr DW, Lemeshow S, Sturdivant RX. Logistic regression for matched case-control studies. John Wiley \& Sons, 2013.

7. Gabriel FS, Gonçalves LFG, Melo EV, Sousa ACS, Pinto IMF, Santana SMM, et al. Placa Aterosclerótica à Angiotomografia de Coronárias em Pacientes com Escore de Cálcio Zero. Arq Bras Cardiol. 2018;110(5):420-7. http://doi.org/10.5935/abc.20180063

8. Arbab-Zadeh A, Carli MFD, Cerci R, George RT, Chen MY, Dewey $\mathrm{M}$, et al. Accuracy of Computed Tomographic Angiography and Single-Photon Emission Computed Tomography-Acquired Myocardial Perfusion Imaging for the Diagnosis of Coronary Artery Disease. Circ Cardiovasc Imaging. 2015;8(10):e003533. http://doi.org/10.1161/CIRCIMAGING.115.003533
9. Ferreira AM, Marques H, Gonçalves PA, Cardim N. Custo-Efetividade de Diferentes Estratégias Diagnósticas de Doença Coronária Estável em Portugal. Arq Bras Cardiol. 2014;102(4):391-402. http://doi.org/10.5935/abc.20140042

10. Silva LS, Rochitte CE. Avaliação da tomografia computadorizada com 64 colunas de detectores em pacientes com síndrome coronária aguda. Tese (Doutorado) - Universidade de São Paulo. São Paulo: 2011.

11. Azevedo CF, Rochitte CE, Lima JA. Escore de cálcio e angiotomografia coronariana na estratificação do risco cardiovascular. Arq Bras Cardiol. 2012;98(6):559-68. http://doi.org/10.1590/S0066-782X2012000600012

12. Budoff M, Dowe D, Jollis J, Gitter M, Sutherland J, Halamert E, et al. Diagnostic performance of 64-multidetector row coronary computed tomographic angiography for evaluation of coronary artery stenosis in individuals without known coronary artery disease: results from the Prospective Multicenter Accuracy (assessment by Coronary Computed Tomographic Angiography of Individuals Undergoing Invasive Coronary Angiography) Trial. J Am Coll Cardiol. 2008:52(21):1724-32. http://doi.org/10.1016/j.jacc.2008.07.031

13. Barros MVL, Rabelo DR, Nunes MCP, Siqueira MHA. Tomografia de coronárias na predição de eventos adversos em pacientes com suspeita de coronariopatia. Arq Bras Cardiol. 2012;99(6):1142-8. http://doi.org/10.1590/S0066-782X2012005000113

14. Won $\mathrm{HH}$, Natarajan $\mathrm{P}$, Dobbyn $\mathrm{A}$, Jordan DM, Roussos $\mathrm{P}$, Lage $\mathrm{K}$, et al. Disproportionate contributions of select genomic compartments and cell types to genetic risk for coronary artery disease. PLoS Genet. 2015;11(10):e1005622. https://doi.org/10.1371/journal.pgen. 1005622

15. Oliveira JLM, Hirata M, Souza A, Gabriel FS, Hirata TDC, Tavares IS, et al. Sexo masculino e hipertensão arterial são preditores de placa à angiotomografia das coronárias. Arq Bras Cardiol. 2015;104(5):409-16. http://doi.org/10.5935/abc.20150028 
16. Cai G, Zhang B, Shi G, Weng W, Ma C, Song Y, et al. The associations between proprotein convertase subtilisin/kexin type 9 E670G polymorphism and the risk of coronary artery disease and serum lipid levels: a meta-analysis. Lipids Health Dis. 2015;14:149. http://doi.org/10.1186/s12944-015-0154-7

17. Conkbayir C, Burak A, Ökçün EB. Lipid variables related to the extent and severity of coronary artery disease in non-diabetic Turkish Cypriots. Iran J Public Health. 2015;44(9):1196.

18. LaBounty TM, Devereux RB, Lin FY, Weinsaft JW, Min JK. Impact of coronary computed tomographic angiography findings on the medical treatment and control of coronary artery disease and its risk factors. Am J Cardiol. 2009;104(7):873-7. http://doi.org/10.1016/j.amjcard.2009.05.024

19. Naito R, Miyauchi K, Konishi H, Tsuboi S, Ogita M, Dohi T, et al. Appropriate level of low-density lipoprotein cholesterol for secondary prevention of coronary artery disease. J Atheroscler Thromb. 2016;23(4):413-21. http://doi.org/10.5551/jat.32284

20. Ogita M, Miyauchi K, Miyazaki T, Naito R, Konishi H, Tsuboi S, et al. Low high-density lipoprotein cholesterol is a residual risk factor associated with long-term clinical outcomes in diabetic patients with stable coronary artery disease who achieve optimal control of low-density lipoprotein cholesterol. Heart Vessels. 2014;29(1):35-41

http://doi.org/10.1007/s00380-013-0330-5

21. Trigatti BL, Fuller M. HDL signaling and protection against coronary artery atherosclerosis in mice. J Biomed Res. 2016;30(2):94. http://doi.org/10.7555/JBR.30.20150079

22. Tavares CAF, Lerario AC. Frequência da doença arterial coronariara (DAC) e características das placas ateroscleróticas avaliadas pela angiotomografia computadorizada multislice em pacientes diabéticos tipo 2 assintomáticos relacionado ao controle glicêmico. Dissertação (Mestrado) - Universidade de São Paulo. São Paulo: 2013.

23. Nicolau JC, Barbosa CJDG, Franci A, Baracioli LM, Franken M, Lima FG, et al. Do diabetic patients with acute coronary syndromes have a higher threshold for ischemic pain? Arq Bras Cardiol. 2014;103(3):183-91. http://dx.doi.org/10.5935/abc.20140106

24. Shaw LJ, Berman DS, Hendel RC, Alazraki N, Krawczynska E, Borges-Neto $\mathrm{S}$, et al. Cardiovascular disease risk stratification with stress single-photon emission computed tomography technetium-99m tetrofosmin imaging in patients with the metabolic syndrome and diabetes mellitus. Am J Cardiol. 2006;97(10):1538-44.

http://doi.org/10.1016/j.amjcard.2005.12.041

25. Potenza MA, Addabbo F, Montagnani M. Vascular actions of insulin with implications for endothelial dysfunction. Am J Physiol Endocrinol Metab. 2009;297(3):E568-77. http://doi.org/10.1152/ajpendo.00297.2009
26. Hofmann MA, Drury S, Fu C, Qu W, Taguchi A, Lu Y, et al. RAGE mediates a novel proinflammatory axis: a central cell surface receptor for S100/calgranulin polypeptides. Cell. 1999;97(7):889-901. http://doi.org/10.1016/s0092-8674(00)80801-6

27. Zhao J, GeX, Vasco-Correa J, Li Y. Fungal pretreatment of unsterilized yard trimmings for enhanced methane production by solid-state anaerobic digestion. Bioresour Technol. 2014;158:248-52. http://doi.org/10.1016/j.biortech.2014.02.029

28. Shah RV, Murthy VL, Colangelo LA, Reis J, Venkatesh BA, Sharma $\mathrm{R}$, et al. Association of fitness in young adulthood with survival and cardiovascular risk: the Coronary Artery Risk Development in Young Adults (CARDIA) Study. Jama Intern Med. 2016;176(1):87-95. http://doi.org/10.1001/jamainternmed.2015.6309

29. Whelton SP, Silverman MG, McEvoy JW, Budoff MJ, Blankstein R, Eng J, et al. Predictors of long-term healthy arterial aging: coronary artery calcium nondevelopment in the MESA study. Cardiovasc Imaging. 2015;8(12):1393-400 http://doi.org/10.1016/j.jcmg.2015.06.019

30. Arslan S, Korkmaz Ö, Özbilüm N, Berkan Ö. Association between

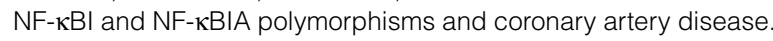
Biomed Rep. 2015;3(5):736-40. http://doi.org/10.3892/br.2015.499

31. Bastami M, Ghaderian S, Omrani M, Mirfakhraie R, NarimanSaleh-Fam Z, Mansoori Y, et al. Evaluating the association of common UBE2Z variants with coronary artery disease in an Iranian population. Cell Mol Biol. 2015;61(7):50-4. https://doi.org/10.14715/cmb/2015.61.7.8

32. Weng L, Taylor KD, Chen Y-DI, Sopko G, Kelsey SF, Merz CNB, et al. Genetic loci associated with nonobstructive coronary artery disease in Caucasian women. Physiol Genomics. 2015;48(1):12-20. http://doi.org/10.1152/physiolgenomics.00067.2015

33. Goldmeier S, Castro I. A teoria do autocuidado no manejo dos fatores de risco (obesidade, hipertensão e tabagismo) em pacientes pós-infarto agudo do miocárdio. Rev AMRIGS. 2005;49(3):149-54.

34. Piryaei M, Ghaderian SMH, Vakili H, Zaimkohan H, Ghahhari NM, Golchin MM. Analysis of rs6725887 in the WD Repeat Protein 12 in Association with Coronary Artery Disease in Iranian Patients. Int $J$ Mol Cell Med. 2015;4(3):160-6.

35. Tavares A. Polimorfismo dos genes do sistema reninaangiotensina-aldosterona e as moléstias cardiovasculares. Rev Bras Hipertens. 2000;7(3):237-42.

36. Oliveira FRF, Resende ES. Acurácia do teste ergométrico no diagnóstico da estenose coronariana após angioplastia com implante de Stent convencional em pacientes assintomáticos. Dissertação (Mestrado) - Universidade Federal de Uberlândia. Uberlândia: 2012.

37. Fornitano LD, Godoy MF. Duplo produto elevado como preditor da ausência de coronariopatia obstrutiva de grau importante em pacientes com teste ergométrico positivo. Arq Bras Cardiol. 2006;86(2):139-44. http://doi.org/10.1590/S0066-782X2006000200010 